\title{
Synthesis, spectroscopy, and theoretical calculations of some 2-thiohydantoin derivatives as possible new fungicides
}

\author{
Katarzyna Kobyłka ${ }^{1} \cdot$ Grzegorz Żuchowski ${ }^{2} \cdot$ Waldemar Tejchman ${ }^{3} \cdot$ Krzysztof K. Zborowski $^{1}$ (D)
}

Received: 23 April 2019 / Accepted: 8 August 2019 / Published online: 24 August 2019

(C) The Author(s) 2019

\begin{abstract}
We present the synthesis and structure determination for two thiohydantoin compounds (5-benzylidene-2sulfanylideneimidazolidin-4-one and 5-cinnamylidene-2-sulfanylideneimidazolidin-4-one), proposed as potential novel fungicides. The exact chemical structure of these molecules has not yet been determined since they can potentially exist in several tautomeric and geometric forms (Z-E isomerism). The geometries of all the theoretically possible structures of the studied compounds were optimised. The calculations were performed at the density functional theory level using the B3LYP functional and the $6-311++\mathrm{G}^{* *}$ basis set. Based on our calculations, the most probable structures of the studied compounds were proposed. The theoretical predictions were verified by comparing the calculated IR as well as the ${ }^{1} \mathrm{H}$ and ${ }^{13} \mathrm{C}$ NMR spectra with the experimental data. It was documented that both the studied compounds exist predominantly in the tautomeric structure, in which the movable hydrogen is connected to the nitrogen atom in the hydantoin ring. It has been experimentally proven that one of the studied compounds occurs only as a single structure, whereas the other one exists as a mixture of two geometric isomers.
\end{abstract}

Keywords 2-thiohydantoin $\cdot$ Theoretical calculations $\cdot$ Tautomerism $\cdot$ Hydantoin $\cdot$ Structure determination

\section{Introduction}

Fungi are a very diverse and widespread group of living organisms. The fungal kingdom is presently considered a separate form of life [1]. Fungi are present in all the climate zones, mainly on land and in the air. It is difficult to evaluate the exact number of fungal species. About a hundred thousand fungi species are classified, but their total number is estimated at greater than five million [2].

This paper belongs to the Topical Collection Zdzislaw Latajka 70th Birthday Festschrift

Electronic supplementary material The online version of this article (https://doi.org/10.1007/s00894-019-4146-9) contains supplementary material, which is available to authorized users.

Krzysztof K. Zborowski

zborowsk@chemia.uj.edu.pl

1 Faculty of Chemistry, Jagiellonian University in Kraków, Gronostajowa 2, 30-387 Kraków, Poland

2 Department of Organic Chemistry, Medical College, Jagiellonian University in Kraków, Medyczna 9, 30-688 Kraków, Poland

3 Department of Chemistry, Institute of Biology, Pedagogical University of Kraków, Podchorążych 2, 30-084 Kraków, Poland
Fungi have both positive and negative impacts on human lives. Saprophytic fungi decompose organic matter. Due to this fact, basic organic compounds are made available again for living organisms [3]. Fungi are also essential to the survival of many groups of organisms with which they form associations $[4,5]$. Fungi are used by humans for numerous purposes. Some mushrooms (fleshy, spore-bearing, fruiting bodies of a fungus) are edible and regarded as dainties. Moreover, numerous kinds of fungi are used in the food industry, in the production of cheese, wine, beer, and baked goods. Fungi are also used in the biotech and pharmaceutical industries, for producing enzymes, vitamins, and antibiotics [6].

On the other hand, fungi can present a risk to human health and life. They cause spoilage of food products, such as fruit, vegetables, milk, meat, and bread; they also contribute to the destruction of industrial materials, such as wood, wool, and cotton [7]. Fungi are also at the root of multiple diseases, including fungal infections and allergies, and are a common cause of poisoning. In addition to humans, other animals and plants are also endangered by pathogenic fungi [8]. Fungi secrete a number of compounds, called mycotoxins, which can have adverse effects on other living organisms; examples are aflatoxins, fumonisins, or patulin [9]. Fungal diseases and 
fungal contamination lead to serious economic and health consequences. A number of chemical compounds, called fungicides, were designed, synthesised, and are used to kill or inhibit fungi and fungal spores [10], which contributes to environmental protection.

Hydantoin (imidazolidine-2,4-dione) is a parent molecule of a large group of compounds used in pharmaceutical and medical applications. Hydantoin derivatives exhibit anticonvulsant, antiarrhythmic, anti-inflammatory, and antibacterial activities [11]; hydantoin thio derivatives are useful and efficient fungicides [12]. In this paper, we concentrate on two derivatives of 2-thiohydantoine (2-sulfanylideneimidazolidin4-one). Along with their fungicidal applications [13], compounds in this group are commonly used as agrochemicals [14], antimutagenics [15], antihypertensives [16], antiinflammatories [17], and metal ion-complexing agents [18]. Hydantoin fungicides are considered to be safe for the environment due to their ability to decompose in the soil and subsequently form biologically inactive components [19]. Therefore, it will be beneficial to conduct further research on these compounds and enhance the knowledge of them.

In this paper, we concentrate on two derivatives of 2thiohydantoine, namely derivatives with 5-benzylidene- and 5-cinnamylidene- substituents. Performed previously research on rhodanine's derivatives has shown that enlarging the substituent size at carbon $\mathrm{C}_{5}$ resulted in increased bioactivity [20, 21]. Thus, synthesis and comparison of biological activities (that will be the topic of a subsequent study) should give us important indications for the strategy of designing hydantoin and rhodanine compounds with biological activity.

\section{Experimental section}

Melting points (uncorrected) were measured on a Boetius apparatus.

The MS settings for the experiments were as follows: flow rate was set to $3 \mu \mathrm{l} / \mathrm{min}$, heated capillary temperature was $280{ }^{\circ} \mathrm{C}$, and capillary voltage was $4.5 \mathrm{kV}$. Scan parameters: scan range $100-1000 \mathrm{~m} / z$, positive ionisation mode. CID fragmentation was carried out in the ion trap analyser with the aid of helium gas. The collision energy was set to ca. $1 \mathrm{~V}$. The samples were introduced into the mass spectrometer in a $\mathrm{CH}_{3} \mathrm{OH}: \mathrm{CHCl}_{3}$ 1:1 solution with $0.1 \% \mathrm{HCOOH}$.

2-Thiohydantoin-3-acetic acid was obtained as shown in the procedure described by E.J. Tarlton and A.F. McKay [22]. 5-benzylidene-2-sulfanylideneimidazolidin-4-one was synthesised and briefly characterised previously [23]. In this work, the condensation of 2-thiohydantoin-3-acetic acid with benzaldehyde and cinnamaldehyde was carried out according to a modified procedure described previously for rhodanine-3acetic acid [24].

\section{General procedure of the synthesis of 5-benzylidene- and 5-cinnamylidene-2- sulfanylideneimidazolidin-4-one}

2-thiohydantoin-3-acetic acid $(0.348 \mathrm{~g}, 2 \mathrm{mmol})$ was dissolved in $25 \mathrm{~cm}^{3}$ of isopropyl alcohol (propan-2-ol). Benzaldehyde or cinnamic aldehyde $(2.5 \mathrm{mmol})$, triethylamine $(1.01 \mathrm{~g}, 10 \mathrm{mmol})$ and molecular sieves $4 \mathrm{~A}$ $(5 \mathrm{~g})$ were added to the obtained solution. The reaction mixture was heated under a reflux condenser for $4 \mathrm{~h}$. After heating, the solution was filtered. Subsequently, the excess of triethylamine was neutralised with a hydrochloric acid solution $(1.0 \mathrm{M})$ and the precipitate was filtered off. The resulting sediment was crystallised from glacial acetic acid. The efficiency of both reactions was moderate.

Compound A: 5-benzylidene-2-sulfanylideneimidazolidin4-one (commonly named 5-benzylidene-2-thiohydantoin-3acetic acid), yield $52.3 \%$, m.p. $258-260^{\circ} \mathrm{C}(\mathrm{EtOH})$, ES MS, $m / z,[\mathrm{M}+1]^{+}$263. Anal. Calc. for formula: $\mathrm{C}_{12} \mathrm{H}_{10} \mathrm{~N}_{2} \mathrm{O}_{3} \mathrm{~S}: \mathrm{C}$, $54.95 \%$, H, 3.84\%, N, $10.68 \%$, Found: C, $54.63 \%$, H, 3.80\%, $\mathrm{N}, 10.55 \%$.

Compound B: 5 - c innamylidene-2 sulfanylideneimidazolidin-4-one (commonly named 5cinnamylidene-2-thiohydantoin-3-acetic acid), yield 56.8\%, m.p. $233-235{ }^{\circ} \mathrm{C}(\mathrm{EtOH}), \mathrm{ES} \mathrm{MS}, m / z,[\mathrm{M}+1]^{+} 289$. Anal. Calc. for formula: $\mathrm{C}_{14} \mathrm{H}_{12} \mathrm{~N}_{2} \mathrm{O}_{3} \mathrm{~S}: \mathrm{C}, 58.32 \%, \mathrm{H}, 4.19 \%, \mathrm{~N}$, 9.72\%, Found: C, $58.32 \%, \mathrm{H}, 4.25 \%, \mathrm{~N}, 9.56 \%$.

\section{Spectroscopic measurements}

The nuclear magnetic resonance spectra were recorded by the Varian Mercury-VX 300 spectrometer operating at $300.08 \mathrm{MHz}\left({ }^{1} \mathrm{H}\right)$ and $75.46 \mathrm{MHz}\left({ }^{13} \mathrm{C}\right)$. The chemical shifts (ppm) were referenced to the residual signal of a solvent. Dimethyl sulfoxide (DMSO- $\mathrm{d}_{6}$ ) was used as the solvent. Dimethyl sulfoxide can strongly interact with solutes and modify their NMR spectra. In order to avoid this effect, we tried using $\mathrm{CCl}_{4}$ and $\mathrm{CDCl}_{3}$ as solvents for the NMR measurements. Unfortunately, the solubility of the studied compounds in $\mathrm{CCl}_{4}$ or $\mathrm{CDCl}_{3}$ is too low to obtain satisfactory NMR spectra. All the spectra were measured at $25^{\circ} \mathrm{C}$.

The IR spectra were measured with the VERTEX 70v Bruker's spectrometer as $\mathrm{KBr}$ disks at the room temperature. The spectral range of $400-4000 \mathrm{~cm}^{-1}$ was covered.

\section{Computational details}

All the theoretical calculations (energies, geometries, vibrational frequencies, chemical shifts) were executed using the Gaussian'03 package [25]. The B3LYP hybrid DFT-HF functional [26] and the 6-311++G** basis set [27] were chosen as the appropriate level of theory. B3LYP is still the most popular DFT method, with plenty of applications. Among others, this 
functional has been used recently (with almost the same as employed in this study $6-311+\mathrm{G}^{* *}$ basis set) to study the tautomerism of the rhodanine molecule [28]. The structural optimisations were followed by the frequency calculations in order to confirm the minimum nature of the calculated geometries. The frequency calculation performed enabled the possibility of enthalpies and free energy calculations for the compounds studied. These properties are the key features in deciding which structures of the compounds studied are the most probable. From free energy values, we can calculate the composition of the tautomeric mixture. This is possible by using the $\Delta \mathrm{G}^{(\mathrm{TA}-\mathrm{TB})}=\mathrm{RT} \ln \mathrm{K}_{\mathrm{T}}{ }^{(\mathrm{TA}-\mathrm{TB})}$ equation, where $\Delta \mathrm{G}^{(\mathrm{TA}-\mathrm{TB})}$ is the free energy gap between a pair of tautomers, $\mathrm{T}$ denotes temperature, $\mathrm{R}$ is the universal gas constant, and $\mathrm{K}_{\mathrm{T}}{ }^{(\mathrm{TA}-\mathrm{TB})}$ represents the constant for the reaction of tautomeric transformation between tautomers $\mathrm{T}_{\mathrm{A}}$ and $\mathrm{T}_{\mathrm{B}}$ [29]. However, in this paper, such calculations were not necessary because the energy gaps between the tautomers of the compounds studied are large. In such a case, only one, the most stable tautomer, is present in the tautomeric mixture.

The calculated theoretical frequencies and intensities were compared with the experimental IR spectra. It is well known that standard DFT calculations overestimate the harmonic frequencies relative to the experimental values. This is due to the electron correlation effects, basic set deficiencies, and harmonicity [30]. Therefore, the calculated harmonic frequencies are scaled down to improve the consistency with the experiment. For that matter, all wavenumbers were multiplied by the scaling factor equal to 0.97 .

The NMR properties (the isotropic chemical shifts for all nuclei of the compounds studied) were calculated using the GIAO method [31] at the same computational level (B3LYP/ 6-311++ $\left.\mathrm{G}^{* *}\right)$ as for geometry optimisation. The tetramethylsilane molecule was used as the reference compound for which we calculated the theoretical reference values for the carbon and hydrogen nuclei used for calculations of relative chemical shifts which were compared with the experimentally measured ones.

All calculations presented here were performed for isolated molecules.

\section{Results and discussion}

In this work, two derivatives of 2-thiohydantoin, compound $\mathbf{A}$ (5-benzylidene-2-thiohydantoin-3-acetic acid) and compound B (5-cinnamylidene-2-thiohydantoin-3-acetic acid), have been synthesised. The antifungal activity of similar compounds was detected [13, 32, 33], so we expect that compounds synthesised here also can have this property. Studies on their antifungal properties are currently being conducted. The schematic presentation of their molecular structures (together with the atom numbering scheme adopted in this work) is provided in Fig. 1. Several tautomeric (in the hydantoin ring and its close environment) and geometric Z-E isomers (in the hydrocarbon substituent connected with the carbon atom $\mathbf{C}_{\mathbf{5}}$ ) are possible. Thus, some details of the studied compounds' structures are not clear. The exact structures of these compounds are interesting, due to their high antifungal activity. Full elucidation of the studied compounds' structures can be useful in the future designing of new fungicides.

\section{Determination of studied compounds' structures}

The first part of the presented research was the theoretical determination of the studied compounds' structures. This task consists of several steps. First of all, the studied compounds have some moveable protons, and, because of that, they can exist in several tautomeric forms. Secondly, two geometrical isomers are possible ( $Z$ and $E$ ) for compound $\mathbf{A}$, and four $(Z, E$, E,Z, Z,Z and E,E) for compound $\mathbf{B}$, due to hindered rotation around $\mathrm{CC}$ double bond(s). Of course, some of the usual problems of conformational analysis around bonds with free rotation are also present.

Six tautomeric structures are possible for both studied compounds. They are all presented in Fig. 2. Three of them $\left(\mathbf{T}_{\mathbf{N H}}\right.$, $\mathbf{T}_{\mathbf{S H}}$, and $\left.\mathbf{T}_{\mathbf{O H}}\right)$ have their carboxyl group protonated $(\mathrm{COOH})$ while the other three tautomers $\left(\mathbf{T}_{\mathbf{N H}-\mathbf{S H}}, \mathbf{T}_{\mathbf{N H}-\mathbf{O H}}\right.$, and $\mathbf{T}_{\mathbf{O H}}$ sH) have the carboxyl group deprotonated $\left(\mathrm{COO}^{-}\right)$. The possible geometrical isomers, common for all tautomers, are presented in Fig. 3.

The geometry optimisation procedure has been performed for all the combinations of the presented tautomers and geometrical isomers, i.e. for twelve structures of compound $\mathbf{A}$ and twenty-four for compound B. The performed calculations show that all tautomeric structures with a deprotonated carboxylic group are unstable because they easily transform into tautomeric structures with the protonated carboxylic group). Thus, only stable $\mathbf{T}_{\mathbf{N H}}, \mathbf{T}_{\mathbf{S H}}$, and $\mathbf{T}_{\mathbf{O H}}$ tautomers will be considered. Their relative enthalpies and free energies (values for the most stable tautomer are assumed as the zero level) are presented in Tables 1 and 2. The data presented in Table 1 indicate that in the case of compound $\mathbf{A}$, the $\mathbf{T}_{\mathbf{N H}}$ tautomer is much more stable than the others. The energy evaluated for the $\mathbf{T}_{\mathbf{N H}}$ tautomer is so low in comparison to all other possible tautomers $\left(\mathbf{T}_{\mathbf{N H}}\right.$ is about $60 \mathrm{~kJ} / \mathrm{mol}$ more stable than $\mathbf{T}_{\mathbf{S H}}$ and about $150 \mathrm{~kJ} / \mathrm{mol}$ than $\mathbf{T}_{\mathbf{O H}}$ ) that even without calculation of the tautomeric equilibria constants we can be sure that only the $\mathbf{T}_{\mathbf{N H}}$ structure should be detectable in the real tautomeric mixture. At the same time, the $\mathbf{Z}$ isomer is about $10 \mathrm{~kJ} / \mathrm{mol}$ more stable than the $\mathbf{E}$ one for all tautomeric structures. In conclusion, we can say that the results of the calculations suggest that the $\mathbf{T}_{\mathbf{N H}}-\mathbf{Z}$ structure should be present almost exclusively in the tautomeric mixture of compound $\mathbf{A}$. The calculated structures of all stable tautomers of compound $\mathbf{A}$, for both $\mathrm{Z}$ and $\mathrm{E}$ isomers, are included in the supplementary data (Fig. S1). 


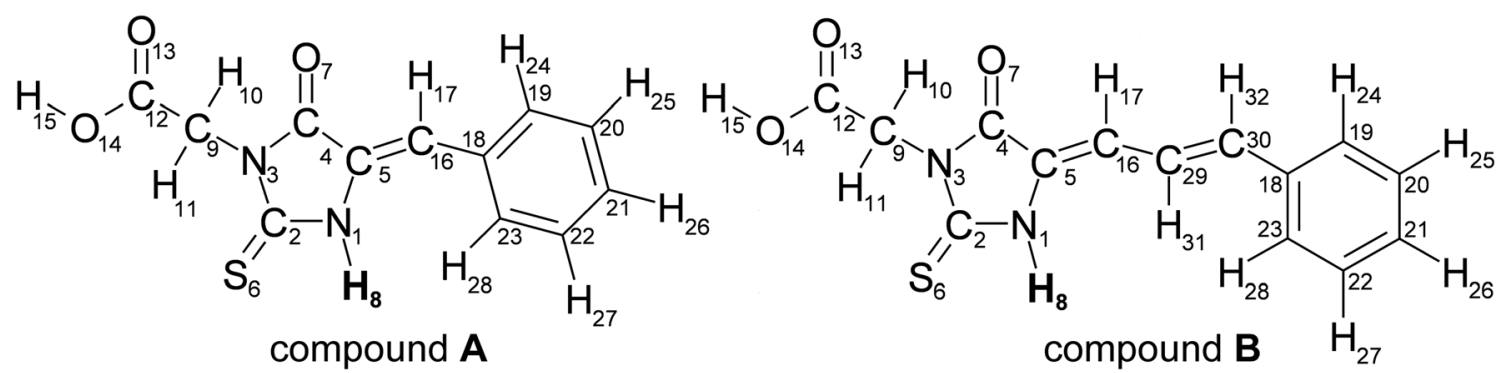

Fig. 1 Studied compounds' molecular structures and atom numbering schemes (Moveable hydrogens are in bold)

The same analysis has been performed for compound $\mathbf{B}$. The corresponding data are presented in Table 2. The same tautomer as for compound $\mathbf{A}$ (the $\mathbf{T}_{\mathbf{N H}}$ one) is the most stable for compound $\mathbf{B}$. It is again followed by tautomers $\mathbf{T}_{\mathbf{S H}}$ (moderate stability) and $\mathbf{T}_{\mathbf{O H}}$ (the lowest stability). The energy differences among tautomers are so high that, again, even without calculations of tautomeric constants, we can say that only tautomer $\mathbf{T}_{\mathbf{N H}}$ should be experimentally detected. The data in Table 2 suggest that conformation $\mathrm{Z}$ is energetically favoured for the double $\mathrm{CC}$ bond being directly connected with the thiohydantoin ring. Another situation, an energetic preference for conformation $\mathrm{E}$, is observed for the second double $\mathbf{C C}$ bond. Structural isomers of compound $\mathbf{B}$, arising from a different combination of Z-E conformations, can be placed into an energetic order $(\mathbf{Z}, \mathbf{E}<\mathbf{E}, \mathbf{E}<\mathbf{Z}, \mathbf{Z}<\mathbf{E}, \mathbf{Z})$ which is valid for all the considered tautomers of compound $\mathbf{B}$. As for compound $\mathbf{A}$, the equilibrium structures of all the tautomers and structural isomers of compound $\mathbf{B}$ are presented in the supplementary data (Fig. S2). For tautomers $\mathbf{T}_{\mathbf{N H}}$ and $\mathbf{T}_{\mathbf{S H}}$, the energetic effects accompanied with the $\mathrm{Z}$ to $\mathrm{E}$ transformation around the $\mathrm{CC}$ double bond connected with the thiohydantoin ring are weaker than in the case of the second $\mathrm{CC}$ bond. The opposite behaviour is observed for tautomer $\mathbf{T}_{\mathbf{O H}}$. The lowest total energy is calculated for the $\mathbf{T}_{\mathbf{N H}}-\mathbf{Z}, \mathbf{E}$ structure. Due to this result, one should expect that the $\mathbf{T}_{\mathbf{N H}^{-}}$ $\mathbf{Z}, \mathbf{E}$ structure dominates in the tautomeric mixture of compound B. However, the predicted energy gaps between geometric $\mathrm{Z}$ and $\mathrm{E}$ isomers are lower than those between the tautomers. Thus, considering the precision of calculations, the theoretical calculations cannot definitively answer the question of which geometrical isomer of the $\mathbf{T}_{\mathbf{N H}}$ tautomer should be experimentally observed. However, from the theoretical point of view, the concentrations of the $\mathbf{Z}, \mathbf{Z}$ and $\mathbf{E}, \mathbf{Z}$ tautomers are expected to be low.

It must be emphasised that there is a fundamental difference between the tautomers and the Z-E isomers. The tautomers are in a dynamic equilibrium in which the tautomer concentrations are determined by the energy gaps among them, and one tautomer can, more or less freely, transform into another one. In contrary, rotation around the $\mathrm{CC}$ double bond is forbidden, since such rotation needs a high amount of energy. Because of that, relative populations of the Z-E isomers depend on the relative energies of transition states of their synthesis reactions and are later frozen. Thus, the population of the Z-E isomers of the chemical compounds can be far away from the thermodynamic equilibrium states that characterise the composition of a tautomeric mixture. The calculations of the transition states' energies for the synthesis reactions of the studied compounds are outside the scope of this work. As a consequence of that, the calculations performed here are expected to determine the approximate composition of a
Fig. 2 Considered tautomeric structures. The names of the tautomers inform us about the location of movable protons. Only the parts of the compounds where tautomerisation takes place is presented<smiles>CC=C1NC(=S)N(CC(=O)O)C1O</smiles>

$\mathbf{T}_{\mathrm{NH}}$<smiles>C/C=C1\NC(=S)N([14CH2]C([13CH3])=O)C1O</smiles>

TNH-SH<smiles>CC=C1N=C(SCC([18OH])[InH])N(C(=O)O)C1=O</smiles><smiles>CC=C1NC(=S)N(CC(=O)O)[C+]1O</smiles><smiles>CC=C1NC(=S)N(C(C)C(=O)[O-])[C+]1O</smiles>

TNH-OH<smiles>CC=C1N=C(S)N(CC(=O)[O-])[C+]1O</smiles>

ToH-SH 
Fig. 3 Possible geometrical isomers (presented for the $\mathrm{T}_{\mathrm{NH}}$ tautomer). In the case of compound $\mathbf{A}$, the name of the isomer informs us about the configuration around the $\mathrm{C}_{5}=\mathrm{C}_{16}$ bond. In the case of compound $\mathbf{B}$, the first part of the geometrical isomer name tells us about the configuration around the $\mathrm{C}_{5}=\mathrm{C}_{16}$ bond, while the second provides information about the configuration around the $\mathrm{C}_{29}=\mathrm{C}_{30}$ bond<smiles>O=C(O)CN1C(=O)/C(=C/c2ccccc2)NC1=S</smiles><smiles>O=C(O)CN1C(=O)/C(=C/c2ccccc2)NC1=S</smiles>

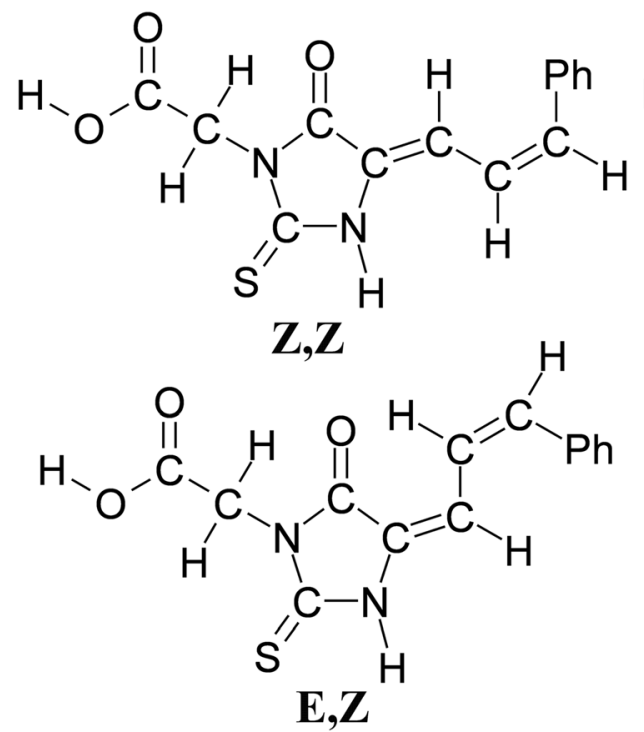<smiles>CC(C(=O)O)N1C(=O)/C(=C/C=C/c2ccccc2)NC1=S</smiles>

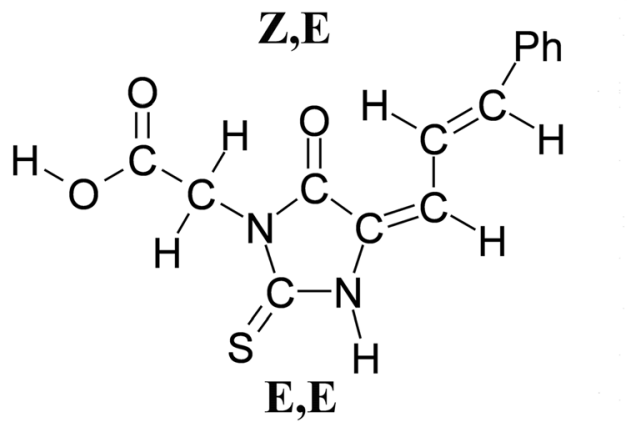

tautomeric mixture, but they do not have to reproduce the relative concentrations of the $\mathrm{Z}-\mathrm{E}$ isomers.

\section{Spectroscopic researches}

In order to validate our theoretical predictions, some spectroscopic measurements (infra-red (IR) as well as nuclear magnetic resonance (NMR)) have been performed for compounds $\mathbf{A}$ and $\mathbf{B}$. The ${ }^{1} \mathrm{H}$ and ${ }^{13} \mathrm{C}$ NMR spectra are available as supplementary data (Figs. S3-S6) and the numerical values of the chemical shifts are in Tables 3 and 4.

The number of signals from the carbon and hydrogen nuclei (without signals resulting from water and DMSO presence) in the experimental NMR spectra of compound $\mathbf{A}$ is the same as the numbers of the carbon and hydrogen atoms in this compound's structure. This indicates that compound A exists in one structure only. The comparison of the

Table 1 Computed relative enthalpies $(\mathrm{H})$ and free energies $(\mathrm{G})$ for different structures of compound $\mathbf{A}$

\begin{tabular}{lcc}
\hline Structure & $\Delta \mathrm{H}[\mathrm{kJ} / \mathrm{mol}]$ & $\Delta \mathrm{G}[\mathrm{kJ} / \mathrm{mol}]$ \\
\hline $\mathbf{T}_{\mathbf{N H}}-\mathbf{Z}$ & 0.00 & 0.00 \\
$\mathbf{T}_{\mathbf{N H}} \mathbf{- E}$ & 10.43 & 11.44 \\
$\mathbf{T}_{\mathbf{S H}} \mathbf{Z}$ & 53.26 & 53.35 \\
$\mathbf{T}_{\mathbf{S H}} \mathbf{- E}$ & 65.92 & 66.48 \\
$\mathbf{T}_{\mathbf{O H}} \mathbf{- Z}$ & 135.66 & 137.31 \\
$\mathbf{T}_{\mathbf{O H}} \mathbf{- E}$ & 168.20 & 170.63 \\
\hline
\end{tabular}

experimental and theoretical chemical shifts (see Table 3) suggests that compound $\mathbf{A}$ exists as tautomer $\mathbf{T}_{\mathbf{N H}}$, for which the lowest energy was theoretically determined. There are several nuclei (for example $\mathrm{C}_{4}, \mathrm{C}_{16}, \mathrm{H}_{11}$, and $\mathrm{H}_{28}$ ) for which calculated chemical shifts for $\mathbf{T}_{\mathbf{N H}}$ are significantly closer to the experimental values than those predicted for other tautomers of compound $\mathbf{A}$. The most predictive for the determination of which geometrical isomer is observed in the experiment should be the theoretical chemical shifts for nuclei $\mathrm{C}_{16}$ and $\mathrm{H}_{17}$, for which the chemical environment changed most

Table 2 Computed relative enthalpies $(\mathrm{H})$ and free energies $(G)$ for different structures of compound $\mathbf{B}$

\begin{tabular}{ccc}
\hline Structure & $\Delta \mathrm{H}[\mathrm{kJ} / \mathrm{mol}]$ & $\Delta \mathrm{G}[\mathrm{kJ} / \mathrm{mol}]$ \\
\hline $\mathbf{T}_{\mathbf{N H}}-\mathbf{Z}, \mathbf{E}$ & 0.00 & 0.00 \\
$\mathbf{T}_{\mathbf{N H}}-\mathbf{E}, \mathbf{E}$ & 0.74 & 2.15 \\
$\mathbf{T}_{\mathbf{N H}} \mathbf{Z}, \mathbf{Z}$ & 14.17 & 15.05 \\
$\mathbf{T}_{\mathbf{N H}}-\mathbf{E}, \mathbf{Z}$ & 17.54 & 19.21 \\
$\mathbf{T}_{\mathbf{S H}}-\mathbf{Z}, \mathbf{E}$ & 55.13 & 55.59 \\
$\mathbf{T}_{\mathbf{S H}}-\mathbf{E}, \mathbf{E}$ & 57.29 & 58.06 \\
$\mathbf{T}_{\mathbf{S H}} \mathbf{Z}, \mathbf{Z}$ & 71.35 & 72.64 \\
$\mathbf{T}_{\mathbf{S H}}-\mathbf{E}, \mathbf{Z}$ & 75.29 & 76.52 \\
$\mathbf{T}_{\mathbf{O H}}-\mathbf{Z}, \mathbf{E}$ & 138.18 & 140.23 \\
$\mathbf{T}_{\mathbf{O H}}-\mathbf{E}, \mathbf{E}$ & 155.34 & 157.28 \\
$\mathbf{T}_{\mathbf{O H}}-\mathbf{Z}, \mathbf{Z}$ & 155.77 & 160.01 \\
$\mathbf{T}_{\mathbf{O H}}-\mathbf{E}, \mathbf{Z}$ & 167.32 & 170.81 \\
\hline
\end{tabular}


Table 3 Experimental chemical shifts of compound $\mathbf{A}$ and theoretical chemical shifts of its considered structures

\begin{tabular}{|c|c|c|c|c|c|c|c|}
\hline \multirow[t]{3}{*}{ Nucleus } & \multirow[t]{3}{*}{$\operatorname{Exp}(\mathrm{ppm})$} & \multicolumn{6}{|c|}{ Theory (B3LYP/6-311++G**, ppm) } \\
\hline & & \multicolumn{2}{|l|}{$\mathbf{T}_{\mathrm{NH}}$} & \multicolumn{2}{|l|}{$\mathbf{T}_{\mathbf{S H}}$} & \multicolumn{2}{|l|}{$\mathbf{T}_{\mathbf{O H}}$} \\
\hline & & $\mathbf{Z}$ & $\mathbf{E}$ & $\mathbf{Z}$ & $\mathbf{E}$ & $\mathbf{Z}$ & $\mathbf{E}$ \\
\hline $\mathrm{C}_{2}$ & 178.81 & 182.31 & 178.87 & 163.50 & 158.42 & 178.90 & 174.79 \\
\hline $\mathrm{C}_{4}$ & 164.02 & 164.01 & 162.65 & 168.71 & 166.74 & 170.28 & 168.46 \\
\hline $\mathrm{C}_{5}$ & 129.29 & 128.69 & 128.51 & 139.10 & 140.93 & 139.36 & 141.68 \\
\hline $\mathrm{C}_{9}$ & 42.25 & 39.93 & 39.93 & 39.26 & 39.63 & 41.64 & 42.66 \\
\hline $\mathrm{C}_{12}$ & 168.61 & 168.74 & 168.90 & 169.69 & 169.75 & 167.72 & 164.85 \\
\hline $\mathrm{C}_{16}$ & 114.06 & 112.88 & 123.14 & 129.27 & 142.24 & 116.63 & 137.39 \\
\hline $\mathrm{C}_{18}$ & 132.51 & 136.51 & 135.67 & 137.10 & 136.83 & 136.75 & 138.02 \\
\hline $\mathrm{C}_{19}$ & 130.84 & 134.58 & 133.13 & 136.09 & 134.89 & 133.96 & 130.92 \\
\hline $\mathrm{C}_{20}$ & 130.84 & 131.12 & 130.82 & 129.32 & 130.50 & 129.00 & 129.42 \\
\hline $\mathrm{C}_{21}$ & 130.09 & 130.42 & 132.47 & 132.08 & 132.88 & 132.78 & 130.79 \\
\hline $\mathrm{C}_{22}$ & 129.29 & 130.78 & 129.59 & 129.78 & 129.27 & 131.04 & 129.81 \\
\hline $\mathrm{C}_{23}$ & 126.37 & 127.27 & 135.27 & 134.68 & 136.91 & 136.60 & 137.48 \\
\hline $\mathrm{H}_{8}$ & 13.23 & 7.70 & 6.90 & 4.34 & 4.31 & 5.96 & 8.49 \\
\hline $\mathrm{H}_{10}$ & 4.49 & 4.45 & 4.45 & 4.68 & 4.77 & 3.69 & 3.63 \\
\hline $\mathrm{H}_{11}$ & 4.49 & 4.38 & 4.51 & 3.57 & 3.60 & 6.09 & 6.69 \\
\hline $\mathrm{H}_{15}$ & 12.55 & 5.54 & 5.62 & 5.69 & 5.69 & 5.60 & 5.88 \\
\hline $\mathrm{H}_{17}$ & 6.69 & 6.65 & 6.14 & 7.01 & 7.17 & 5.65 & 7.61 \\
\hline $\mathrm{H}_{24}$ & 7.77 & 7.42 & 9.95 & 7.43 & 10.04 & 7.17 & 8.36 \\
\hline $\mathrm{H}_{25}$ & 7.42 & 7.42 & 7.47 & 7.30 & 7.47 & 7.31 & 7.28 \\
\hline $\mathrm{H}_{26}$ & 7.42 & 7.24 & 7.36 & 7.30 & 7.37 & 7.36 & 7.12 \\
\hline $\mathrm{H}_{27}$ & 7.44 & 7.44 & 7.38 & 7.38 & 7.40 & 7.53 & 7.42 \\
\hline $\mathrm{H}_{28}$ & 7.79 & 7.53 & 7.18 & 9.24 & 7.39 & 9.90 & 7.50 \\
\hline
\end{tabular}

significantly during the Z-E transition. The theoretical calculations for both of these nuclei strongly suggest that $\mathbf{T}_{\mathbf{N H}}-\mathbf{Z}$ is solely observed experimentally for compound $\mathbf{A}$. In order to validate this conclusion, we calculated the correlations between the experimental data and different sets of the theoretically calculated chemical shifts. The correlation coefficients are stored in Table S3 (supplementary data). The best fits to experimental data $\left(R^{2}=0.997\right.$ for ${ }^{13} \mathrm{C}$ NMR and 0.992 for ${ }^{1} \mathrm{H}$ NMR) were obtained for the chemical shifts calculated for the $\mathbf{T}_{\mathbf{N H}} \mathbf{Z}$ structure. Lower $\left({ }^{13} \mathrm{C}\right.$ NMR) and much lower $\left({ }^{1} \mathrm{H}\right.$ NMR) square correlation coefficients were obtained for other possible structures of compound $\mathbf{A}$.

In general, the agreement between the calculated and experimental chemical shifts is satisfactory. A different situation is noticed only for more acidic protons $\mathrm{H}_{8}$ and $\mathrm{H}_{15}$. The signal of the proton of the carboxylic group is present between 10 and $13 \mathrm{ppm}$. Thus, the signal at $12.55 \mathrm{ppm}$ is assigned to the $\mathrm{COOH}$ proton. But this is not the most downfield signal in the ${ }^{1} \mathrm{H}$ NMR spectrum of compound $\mathbf{A}$. The most downfield signal, at $13.23 \mathrm{ppm}$, must be attributed to the moveable $\mathrm{H}_{8}$ proton. Such a high chemical shift should not be observed for the $\mathrm{H}_{8}$ proton in any tautomeric form of compound $\mathbf{A}$.
However, it must be once more emphasised that for the NMR measurements, compounds $\mathbf{A}$ and $\mathbf{B}$ were dissolved in DMSO- $\mathrm{d}_{6}$, which is quite an aggressive chemical medium and can strongly interact with solute molecules. Such interactions are especially intense for the "acidic" hydrogens that are a part of groups such as $\mathrm{OH}$ or $\mathrm{NH}$. The $\mathrm{H}_{8}$ proton is a part of such groups: $\mathrm{OH}, \mathrm{NH}$, or $\mathrm{SH}$, depending on the tautomeric form. Thus, such an enormous shift for the $\mathrm{H}_{8}$ signal is caused by solution of the NH group proton by DMSO molecule(s). The solvent molecule(s) are not included in the calculation and this is the reason why the calculated chemical shift value is very far from the experimental one for this nucleus. A similar phenomenon was observed by us in case of barbituric acid, where the detailed calculations for barbituric acid solvated by DMSO molecule(s) were performed [34].

A part of the experimental IR spectrum of compound $\mathbf{A}$, from 400 to $2000 \mathrm{~cm}^{-1}$, has been chosen for comparison with the theoretical data (see Fig. 4). The experimental spectrum is dominated by three groups of vibrational bands. These groups were used for comparing with the results of the theoretical calculations. The first group is positioned between 1600 and $1800 \mathrm{~cm}^{-1}$ and consists of two broad bands with different 
Table 4 Experimental chemical shifts of compound B and theoretical chemical shifts of different geometrical isomers-tautomer $\mathbf{T}_{\mathbf{N H}}$

\begin{tabular}{|c|c|c|c|c|c|}
\hline Nucleus & $\operatorname{Exp}(p p m)$ & $\mathbf{Z}, \mathbf{E}$ & $\mathbf{E}, \mathbf{E}$ & $\mathbf{Z}, \mathbf{Z}$ & $\mathbf{E}, \mathbf{Z}$ \\
\hline $\mathrm{C}_{2}$ & $176.37,175.18$ & 179.95 & 179.04 & 180.14 & 179.20 \\
\hline $\mathrm{C}_{4}$ & $162.97,162.33$ & 163.23 & 162.99 & 163.44 & 162.66 \\
\hline $\mathrm{C}_{5}$ & $122.76,122.50$ & 127.18 & 126.97 & 129.82 & 129.29 \\
\hline $\mathrm{C}_{9}$ & 42.00 & 39.67 & 39.46 & 39.73 & 39.37 \\
\hline $\mathrm{C}_{12}$ & 168.67 & 168.90 & 169.10 & 168.83 & 168.86 \\
\hline $\mathrm{C}_{16}$ & 114.69 & 113.17 & 120.32 & 109.36 & 115.49 \\
\hline $\mathrm{C}_{18}$ & $136.83,136.74$ & 137.95 & 138.49 & 139.43 & 139.72 \\
\hline $\mathrm{C}_{19}$ & 129.66 & 133.83 & 126.56 & 130.67 & 131.79 \\
\hline $\mathrm{C}_{20}$ & 127.81 & 130.62 & 129.96 & 129.84 & 130.82 \\
\hline $\mathrm{C}_{21}$ & 127.40 & 131.53 & 130.98 & 130.83 & 129.67 \\
\hline $\mathrm{C}_{22}$ & 127.59 & 130.29 & 130.20 & 130.28 & 129.52 \\
\hline $\mathrm{C}_{23}$ & 129.43 & 124.69 & 133.36 & 132.02 & 130.53 \\
\hline $\mathrm{C}_{29}$ & 119.96 & 119.25 & 125.19 & 121.22 & 126.18 \\
\hline $\mathrm{C}_{30}$ & $141.07,140.84$ & 144.19 & 146.64 & 142.82 & 142.29 \\
\hline $\mathrm{H}_{8}$ & 13.20 & 7.26 & 6.88 & 7.31 & 6.87 \\
\hline $\mathrm{H}_{10}$ & 4.44 & 4.38 & 4.48 & 4.42 & 4.40 \\
\hline $\mathrm{H}_{11}$ & 4.44 & 4.34 & 4.40 & 4.30 & 4.30 \\
\hline $\mathrm{H}_{15}$ & $12.72,12.51$ & 5.55 & 5.58 & 5.56 & 5.55 \\
\hline $\mathrm{H}_{17}$ & $6.58,6.54$ & 6.37 & 6.03 & 6.86 & 6.57 \\
\hline $\mathrm{H}_{24}$ & $7.54,7.57$ & 7.21 & 8.08 & 7.72 & 7.23 \\
\hline $\mathrm{H}_{25}$ & 7.41 & 7.32 & 7.32 & 7.42 & 7.43 \\
\hline $\mathrm{H}_{26}$ & 7.38 & 7.25 & 7.18 & 7.37 & 7.25 \\
\hline $\mathrm{H}_{27}$ & 7.36 & 7.37 & 7.28 & 7.42 & 7.30 \\
\hline $\mathrm{H}_{28}$ & $7.58,7.62$ & 7.83 & 7.07 & 7.40 & 7.48 \\
\hline $\mathrm{H}_{31}$ & $7.18,7.15$ & 6.97 & 8.66 & 6.10 & 7.87 \\
\hline $\mathrm{H}_{32}$ & $7.13,7.10$ & 6.90 & 6.74 & 7.00 & 6.99 \\
\hline
\end{tabular}

intensities. The second is located around $1400 \mathrm{~cm}^{-1}$. Several overlapping bands are present in this group. The last of these characteristic groups is situated between 900 and $1300 \mathrm{~cm}^{-1}$ and possesses three intense bands. Many medium-intensity bands are also present between 900 and $400 \mathrm{~cm}^{-1}$, but there are no characteristic points for comparison with theory there.

It can be simply noticed that the weakest similarity between the theoretical and experimental IR spectra is observed for both geometric isomers of the $\mathbf{T}_{\mathbf{O H}}$ tautomer. There are two theoretically predicted bands between 1600 and $1800 \mathrm{~cm}^{-1}$, but the distance between them is too big, especially for the $\mathbf{T}_{\mathbf{O H}}-\mathbf{E}$ structure. In addition to this, the shape of other groups of the bands from the theoretical $\mathbf{T}_{\mathbf{O H}}$ spectrum is not similar to the experimental pattern. In addition, they are located in narrower ranges than those in the experimental spectrum. The calculated spectra of the $\mathbf{T}_{\mathbf{S H}}$ tautomer also do not correspond well with the experimental data. The biggest differences in bands' positions, as well as in bands' intensities, are observed in the $1300-1550 \mathrm{~cm}^{-1}$ range. In contrast, the theoretical spectra of the $\mathbf{T}_{\mathbf{N H}}$ tautomer fit the experimental data much more closely. All three groups of bands mentioned above are present. In addition, the theoretical spectrum of $\mathbf{T}_{\mathbf{N H}}-\mathbf{Z}$ is more similar to the experiment than the $\mathbf{T}_{\mathbf{N H}}-\mathbf{E}$ one, especially in the $900-1300 \mathrm{~cm}^{-1}$ region.

In conclusion, it can be said that theoretical vibrational spectrum of the $\mathbf{T}_{\mathbf{N H}}-\mathbf{Z}$ structure of compound $\mathbf{A}$ is the most similar one to the experimental IR spectrum. Thus, the results of the IR analysis are consistent with the NMR and quantummechanical predictions.

The experimental NMR data of compound $\mathbf{B}$ are more complicated than those observed for compound A, see Figs. S5 and S6, supplementary data. The examination of the compound $\mathbf{B}$ spectra reveals that the chemical shifts of two structures are present in the experimental spectra. It can be estimated, from the ${ }^{1} \mathrm{H}$ NMR spectrum, that one of them is present at a much lower concentration. The calculations of relative concentrations of these two isomers have been performed for three pairs of signals observed in the ${ }^{1} \mathrm{H}$ NMR spectrum of compound B (12.72/12.51 ppm, 7.18/7.15 ppm, and 7.13/ $7.10 \mathrm{ppm}$ ). Each of these pairs consists of a signal from the dominant structure and a satellite signal from the structure with the lower concentration. The first being the chemical shift of the main band and the second being the chemical shift of the satellite band. The calculated percentage concentrations of the structure with the lower concentration are 8.86, 15.67, and 14.33, respectively. Thus, compound $\mathbf{B}$ is a mixture of two isomers with concentrations of about $83 \%$ (the structure with higher concentration) and $13 \%$ (the structure with lower concentration).

As previously, we correlated the experimental chemical shifts with the theoretical ones and calculated for different structures of compound $\mathbf{B}$ (see Table S3, supplementary data). Similar to, and for the same reasons as for compound $\mathbf{A}$, the experimental values of protons $\mathrm{H}_{8}$ and $\mathrm{H}_{15}$ are far from the results of the theoretical calculations. The chemical shifts of these protons are omitted in the correlations mentioned. The calculated correlation coefficients support the theoretical prediction presented earlier that experimentally compound $\mathbf{B}$ should be dominated by the $\mathbf{T}_{\mathbf{N H}}$ tautomer. For other tautomers of compound $\mathbf{B}$, correlations are significantly worse. Good indicators of the presence of the $\mathbf{T}_{\mathbf{N H}}$ tautomer in the experiment are the theoretical chemical shifts of $\mathrm{C}_{4}, \mathrm{C}_{5}$, and $\mathrm{H}_{11}$ nuclei that fit the experimental data much more closely for $\mathbf{T}_{\mathbf{N H}}$ than for other tautomers. Because of that, in the presented paper, the theoretical chemical shifts are present only for the $\mathbf{T}_{\mathbf{N H}}$ tautomer (see Table 4). The obtained results of the calculations for $\mathbf{T}_{\mathbf{S H}}$ and $\mathbf{T}_{\mathbf{O H}}$ tautomers are available in the supplementary data (see Tables S1 and S2, respectively). Among possible geometrical isomers of the tautomer $\mathbf{T}_{\mathbf{N H}}$, the theoretically most stable $\mathbf{T}_{\mathbf{N H}}-\mathbf{Z}, \mathbf{E}$ isomer has been identified as the best fit to the experimental data. Comparison of the theoretical and experimental chemical shifts of the 16,23 , and 29 carbon nuclei decisively supports this prediction. Most 

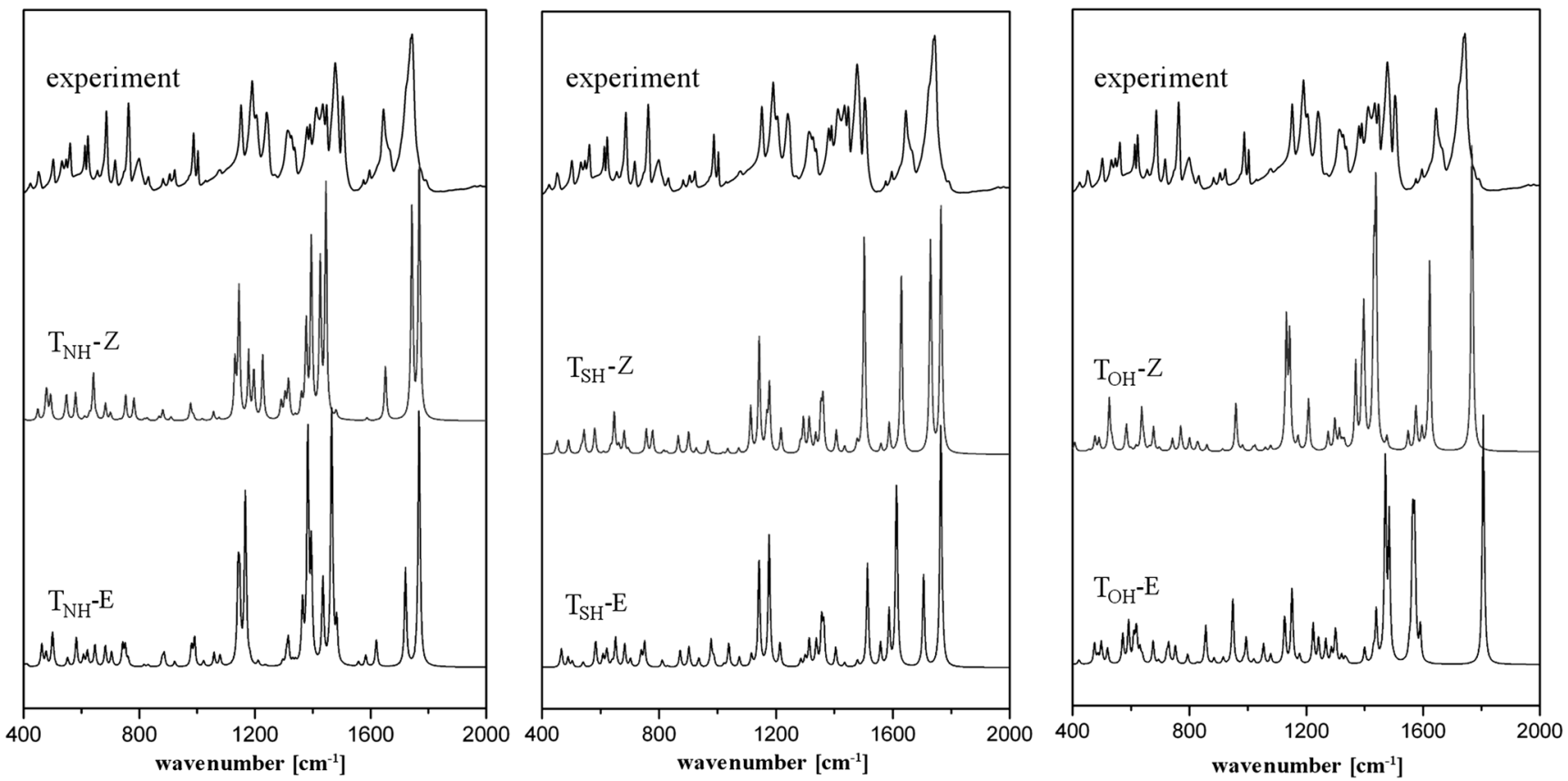

Fig. 4 Experimental and calculated (B3LYP/6-311++G**) IR spectra of compound A

notably, carbons 16 and 29, which are part of the CC double bonds in compound $\mathbf{B}$, are the ones of crucial importance. However, the same correlation coefficient for the ${ }^{13} \mathrm{C} N M R$ data and only slightly lower correlation coefficient for ${ }^{1} \mathrm{H}$ NMR have been obtained for the $\mathbf{T}_{\mathbf{N H}}-\mathbf{E}, \mathbf{Z}$ structure. The $\mathbf{T}_{\mathbf{N H}}-\mathbf{E}, \mathbf{Z}$ isomer is in the fourth place in the energetic order of the $\mathbf{T}_{\mathbf{N H}}$ geometrical isomers (see Table 2). Thus, the presence of this structure in the experiment has not been expected. Much more probable was the detection of the isomer $\mathbf{T}_{\mathbf{N H}}{ }^{-}$ $\mathbf{E}, \mathbf{E}$, whose calculated energy is only slightly higher than of the $\mathbf{T}_{\mathbf{N H}}-\mathbf{Z}, \mathbf{E}$ isomer. However, the correlation between the theoretical chemical shifts of $\mathbf{T}_{\mathbf{N H}}-\mathbf{E}, \mathbf{E}$ and the experimental data is poorer than for other isomers. As it was stated above, the relative concentrations of the geometric isomers are determined by the differences in the energies of the transition states during the synthesis. It is probable that the transition state leading to the $\mathbf{T}_{\mathbf{N H}}-\mathbf{E}, \mathbf{Z}$ isomer formation has relatively low energy. It should be also mentioned that the possibility of geometric isomer with higher energy formation (in small amount) was also documented in similar compounds [35] Considering the above-mentioned, we can conclude that in the experimental NMR spectra, two isomers $\mathbf{T}_{\mathbf{N H}}-\mathbf{Z}, \mathbf{E}$ (high concentration) and $\mathbf{T}_{\mathbf{N H}}-\mathbf{E}, \mathbf{Z}$ (low concentration) are observed.

The experimental and calculated vibrational spectra of compound $\mathbf{B}$ are shown in Fig. 5. The analysis of the experimental spectrum of compound $\mathbf{B}$ seems not to be an easy task because the compound exists as a mixture of two different geometrical isomers (as it was deduced above from the NMR spectra). Fortunately, the second structure is in a rather low concentration that is almost negligible for the less sensitive IR spectroscopy. Thus, its bands should be only slightly present in the spectrum and their detection difficult. Similar to the spectrum of compound $\mathbf{A}$, here we can also separate three groups of vibrational bands. In the first group (1600-1800 $\left.\mathrm{cm}^{-1}\right)$, one very intense and broad band (with its maximum slightly above $1700 \mathrm{~cm}^{-1}$ ) and two smaller bands (about $1600 \mathrm{~cm}^{-1}$ ) are observed. The second group is dominated by two intense bands around $1300 \mathrm{~cm}^{-1}$. Finally, the third group (900-1250 $\mathrm{cm}^{-1}$ ) has three intense, partially overlapping bands. An overview of the patterns of the calculated spectra assure us that only the $\mathbf{T}_{\mathbf{N H}}-\mathbf{Z}, \mathbf{E}$ structure can be responsible for the shape of the obtained experimental vibrational spectrum. Only in the theoretical spectrum of the $\mathbf{T}_{\mathbf{N H}}-\mathbf{Z}, \mathbf{E}$ isomer can we find, at the same time, the bands corresponding to all abovedescribed key features of the experimental spectrum of compound B. There are, in the calculated spectrum of the $\mathbf{T}_{\mathbf{N H}}-\mathbf{Z}, \mathbf{E}$ structure, two strong bands that together can form the strong band above $1700 \mathrm{~cm}^{-1}$. There are also two strong bands corresponding to the two intense bands around $1300 \mathrm{~cm}^{-1}$ (certainly the half-width for one of them should be increased in the theoretical spectrum, but we prefer to use only one half-width for all the theoretical bands). Even the complicated shape of the third group of the experimental bands has quite similar counterparts in the theoretical spectrum of the $\mathbf{T}_{\mathbf{N H}}-\mathbf{Z}, \mathbf{E}$ isomer. Thus, the comparison of the theoretical and experimental IR data strongly supports the thesis that the $\mathbf{T}_{\mathbf{N H}}-\mathbf{Z}, \mathbf{E}$ structure is the main component of the mixture observed for compound $\mathbf{B}$. 

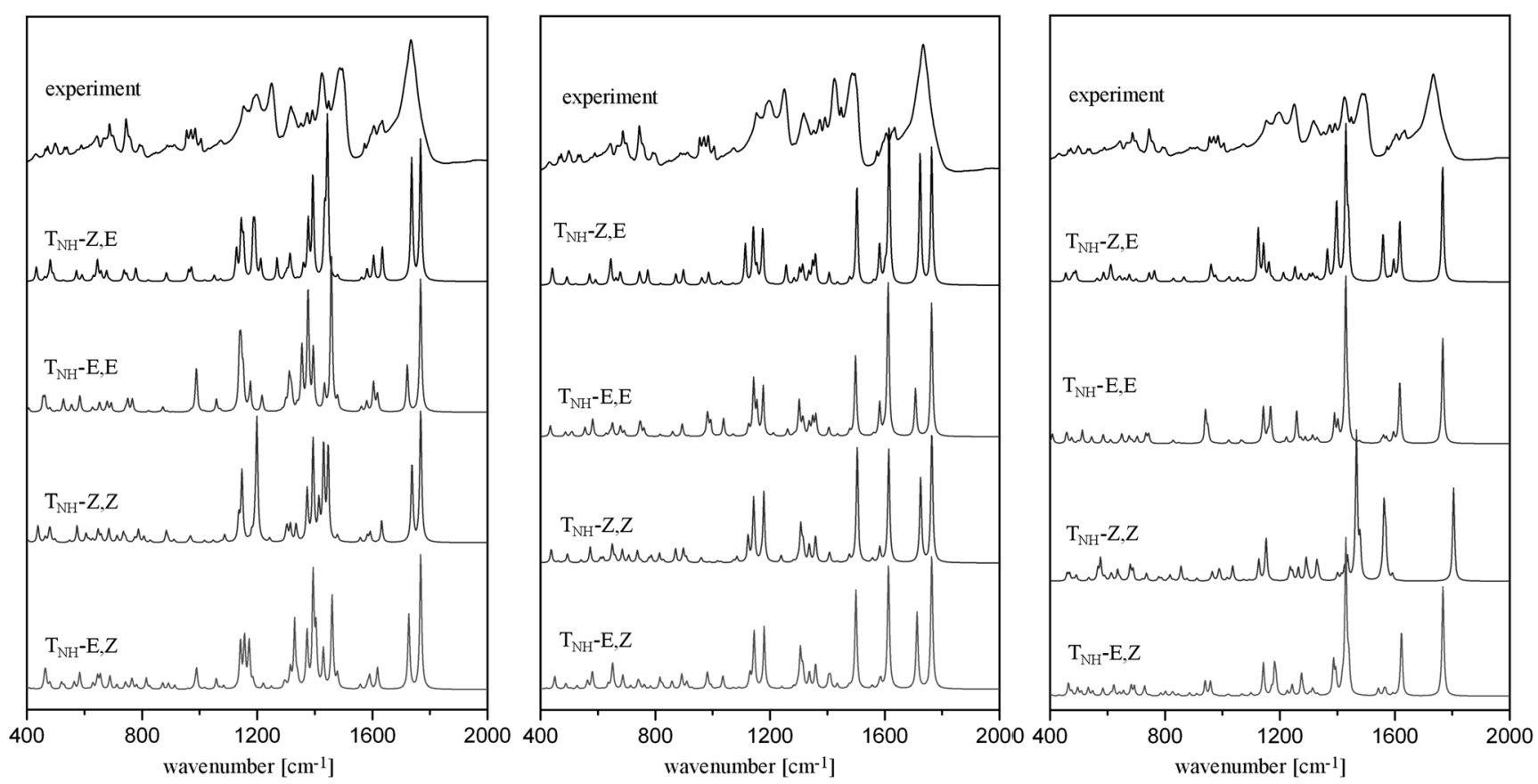

Fig. 5 Experimental and calculated (B3LYP/6-311++G**) IR spectra of compound $\mathbf{B}$

\section{Conclusions}

The main goal of this work can be summarised as the determination of the structural and spectroscopic properties of two thiohydantoin derivatives, for which good antifungal properties have been briefly confirmed. This goal has been achieved by measuring some experimental data (IR and NMR) and comparing them with the results of the theoretical calculations obtained for isolated molecules of studied compounds.

Conclusions from the performed research are the following:

- Provided quantum chemical calculations evaluated the $\mathbf{T}_{\mathbf{N H}}$ tautomer, in which the nitrogen atom is protonated, as the most stable one. The calculated relative energies of other tautomers are significantly higher, so tautomer $\mathbf{T}_{\mathbf{N H}}$ should be solely present in the tautomeric mixtures of both compounds studied.

- The carboxylic group is always protonated. The tautomers with a deprotonated carboxylic group transform easily into the protonated ones during the geometry optimisation procedure.

- Among possible geometrical isomers, the most stable in calculations are isomers $\mathbf{Z}$ (compound $\mathbf{A}$ ) and $\mathbf{Z , E}$ (compound $\mathbf{B})$.

- The spectroscopic data fully support the theoretical predictions for compound $\mathbf{A}$. It seems that compound $\mathbf{B}$ is a mixture of the most theoretically stable $\mathbf{T}_{\mathbf{N H}}-\mathbf{Z}, \mathbf{E}$ isomer (at a high concentration) and the $\mathbf{T}_{\mathbf{N H}}-\mathbf{E}, \mathbf{Z}$ isomer (at a low concentration).
Acknowledgements The FT-IR research and theoretical calculations were carried out with the equipment purchased thanks to the financial support of the European Regional Development Fund in the framework of the Polish Innovation Economy Operational Program (contract no. POIG.02.01.00-12-023/08).

Open Access This article is distributed under the terms of the Creative Commons Attribution 4.0 International License (http:// creativecommons.org/licenses/by/4.0/), which permits unrestricted use, distribution, and reproduction in any medium, provided you give appropriate credit to the original author(s) and the source, provide a link to the Creative Commons license, and indicate if changes were made.

\section{References}

1. Kirk PM, Cannon PF, Minter DW, Stalpers JA (2008) Dictionary of the fungi10th edn. CAB International, Wallingford

2. Blackwell M (2011) The fungi: 1, 2, 3 ... 5.1 million species? Am J Bot 98:426-438. https://doi.org/10.3732/ajb.1000298

3. Webster J, Weber R (2007) Introduction to fungi3rd edn. Cambridge University Press, Cambridge

4. States JS, Christensen M (2001) Fungi associated with biological soil crusts in desert grasslands of Utah and Wyoming. Mycologia 93:432-439. https://doi.org/10.2307/3761728

5. Varma A (2008) Mycorrhiza. Springer-Verlag, Berlin Heidelberg

6. Hofrichter M (2011) The Mycota X, industrial applications2nd edn. Springer-Verlag, Berlin Heidelberg

7. Deising HB (2009) The Mycota V, Plant relationships2nd edn. Springer-Verlag, Berlin Heidelberg

8. Olsen L, Choffnes ER, Relman DA, Pray L (2011) Fungal diseases. An emerging threat to human, animal and plant health. the National Academies Press, Washington D.C

9. Koong LJ, Gruber TA, Chimenti LM Mycotoxins: Risk in plant, animal and human systems. Council for Agricultural Science and Technology, Ames 
10. Oliver R, Hewitt HG (2014) Fungicides in crop protection2nd edn. $\mathrm{CAB}$ International, Wallingford

11. Mosby (2009) Mosby's medical dictionary8th edn. Elsevier, Amsterdam

12. Carisse O, Tremblay DM, Jobin T, Walker AS (2010) Disease decision support systems: their impact on disease management and durability of fungicide effectiveness. In: Carisse $\mathrm{O}$ (ed) Fungicides. Intech, Rijeka, pp 177-200

13. El Hady HA (2012) Syntheses and antimicrobial activity of some new thiohydantoin and thiazole derivatives. Der Pharma Chemica 4:2202-2207

14. Deval V, Kumar A, Gupta V, Sharma A, Gupta A, Tandon P, Kunimoto K (2014) Molecular structure (monomeric and dimeric) and hydrogen bonds in 5-benzyl 2-thiohydantoin studied by FT-IR and FT-Raman spectroscopy and DFT calculations. Spectrochim Acta A 132:15-26. https://doi.org/10.1016/j.saa.2014.04.101

15. Takahashi A, Matsuoka H, Ozawa Y, Uda Y (1998) Antimutagenic properties of 3,5-disubstituted 2-thiohydantoins. J Agric Food Chem 46:5037-5042. https://doi.org/10.1021/jf980430x

16. Dylag T, Zygmunt M, Maciag D, Handzlik J, Bednarski M, Filipek B, Kiec-Kononowicz K (2004) Synthesis and evaluation of in vivo activity of diphenylhydantoin basic derivatives. Eur J Med Chem 39:1013-1027. https://doi.org/10.1016/j.ejmech.2004.05.008

17. Vang ZD, Sheikh SO, Zhang Y (2006) A simple synthesis of 2thiohydantoins. Molecules 11:739-750. https://doi.org/10.3390/ 11100739

18. Metwally MA, Abdel-Latif E (2012) Thiohydantoins: synthetic strategies and chemical reactions. J Sulfur Chem 33:229-257. https://doi.org/10.1080/17415993.2011.643550

19. Marton J, Enisz J, Hosztafi S, Timar T (1993) Preparation and fungicidal activity of 5-substituted hydantoins and their 2-thio analogs. Agr Food Chem 41:148-152. https://doi.org/10.1021/ jf00025a031

20. Tejchman W, Korona-Głowniak I, Malm A, Żylewski M, Suder P (2017) Antibacterial properties of 5-substituted derivatives of rhodanine-3-carboxyalkyl acids. Med Chem Res 26:1316-1324. https://doi.org/10.1007/s00044-017-1852-7

21. Pardasani RT, Pardasani P, Sherry D, Chaturvedi V (2001) Synthetic and antibacterial studies of rhodanine derivatives with indol 2,3-diones. Indian J Chem B 40:1275-1278

22. Tarlton EJ, McKay AF (1958) Amino acids: IV. The reaction of glycine and $\beta$-alanine with carbon disulphide. Can J Chem 36:496-506

23. Korohoda MJ (1981) Introduction of selenium into heterocyclic compounds. Part II. Synthesis of 3-alkyl2-selenohydantoins, 2selenohydantoin-3-acetic acids and 2-selenorhodanines with double bond at C-5. Polish J Chem 55:359-369

24. Żesławska E, Nitek W, Tejchman W (2015) The synthesis and crystal structures of the homologues of epalrestat. J Chem Crystallogr 45:151-157. https://doi.org/10.1007/s10870-0150577-z

25. Frisch MJ, Trucks GW, Schlegel HB, Scuseria GE, Robb MA, Cheeseman JR, Montgomery Jr JA, Vreven T, Kudin KN, Burant JC, Millam JM, Iyengar SS, Tomasi J, Barone V, Mennucci B, Cossi M, Scalmani G, Rega N, Petersson GA, Nakatsuji H, Hada
M, Ehara M, Toyota M, Fukuda R, Hasegawa J, Ishida M, Nakajima T, Honda Y, Kitao O, Nakai H, Klene M, Li X, Knox JE, Hratchian HP, Cross JP, Bakken V, Adamo C, Jaramillo J, Gomperts R, Stratmann RE, Yazyev O, Austin AJ, Cammi R, Pomelli C, Ochterski JW, Ayala PY, Morokuma K, Voth GA, Salvador P, Dannenberg JJ, Zakrzewski VG, Dapprich S, Daniels AD, Strain MC, Farkas O, Malick DK, Rabuck AD, Raghavachari K, Foresman JB, Ortiz JV, Cui Q, Baboul AG, Clifford SA, Cioslowski J, Stefanov BB, Liu G, Liashenko A, Piskorz P, Komaromi I, Martin RL, Fox DJ, Keith T, Al-Laham MA, Peng CY, Nanayakkara A, Challacombe B, Gill PM, Johnson B, Chen W, Wong MW, Gonzalez C, Pople JA (2004) Gaussian'03, Revision E.01. Gaussian, Inc., Wallingford

26. Becke AD (1993) Density-functional thermochemistry. III. The role of exact exchange. J Chem Phys 98:5648-5652. https://doi.org/10. $1063 / 1.464913$

27. McLean AD, Chandler GS (1980) Contracted Gaussian basis sets for molecular calculations. I. Second row atoms, $Z=11-18$. J Chem Phys 72:5639-5648. https://doi.org/10.1063/1.438980

28. Faris WM, Safi ZS (2014) Theoretical investigation on tautomerism stability of hydantoin in the gas phase and in the solution. Orient $\mathrm{J}$ Chem 30:1045-1054. https://doi.org/10.13005/ojc/300316

29. Hobza P, Sponer J (1999) Structure, energetics, and dynamics of the nucleic acid base pairs: nonempirical ab initio calculations. Chem Rev 99:3247-3276. https://doi.org/10.1021/cr9800255

30. Sundaraganesan N, Ilakiamani S, Saleem H, Wojciechowski PM, Michalska D (2005) FT-Raman and FT-IR spectra, vibrational assignments and density functional studies of 5-bromo-2nitropyridine. Spectrochim Acta A 61:2995-3001. https://doi.org/ 10.1016/j.saa.2004.11.016

31. Woliński K, Hilton JF, Pulay P (1990) Efficient implementation of the gauge-independent atomic orbital method for NMR chemical shift calculations. J Am Chem Soc 112:8251-8260. https://doi.org/ 10.1021/ja00179a005

32. Pansare DN, Shelke RN, Khade MC, Jadhav VN, Pawar CD, Jadhav RA, Bembalkar SR (2019) New thiazolone derivatives: design, synthesis, anticancer and antimicrobial activity. Eur Chem Bull 8:7-14. https://doi.org/10.17628/ecb.2019.8.7-14

33. Tang B, Yang M, Zhao Y, Kong L, Wang W, Wang M (2015) Discovery of 5-(5,5-dimethylbutenolide-3-ethylidene)-2aminoimidazolinone derivatives as fungicidal agents. Molecules 20:13740-13752. https://doi.org/10.3390/molecules200813740

34. Żuchowski G, Zborowski K (2006) The influence of solvent molecules on NMR spectrum of barbituric acid in the DMSO solution. Cent Eur J Chem 4:523-532. https://doi.org/10.2478/ s11532-006-0019-z

35. Mendgen T, Steuer C, Klein CD (2012) Privileged scaffolds or promiscuous binders: a comparative study on rhodanines and related heterocycles in medicinal chemistry. J Med Chem 55:743-753. https://doi.org/10.1021/jm201243p

Publisher's note Springer Nature remains neutral with regard to jurisdictional claims in published maps and institutional affiliations. 